\title{
Development of Four Unit Processes for Biobased PLA Manufacturing
}

\author{
Chae Hwan Hong, Si Hwan Kim, Ji-Yeon Seo, and Do Suck Han
}

Central Research Institute, Hyundai-Kia Motor Company, Republic of Korea

Correspondence should be addressed to Chae Hwan Hong, hong@hyundai.com

Received 30 December 2011; Accepted 18 January 2012

Academic Editors: L. Avérous and A. V. Popov

Copyright (๑) 2012 Chae Hwan Hong et al. This is an open access article distributed under the Creative Commons Attribution License, which permits unrestricted use, distribution, and reproduction in any medium, provided the original work is properly cited.

Polylactide (PLA), which is one of the most important biocompatible polyesters that are derived from annually renewable biomass such as corn and sugar beets, has attracted much attention for automotive parts application. The manufacturing method of PLA is the ring-opening polymerization of the dimeric cyclic ester of lactic acid, lactide. For the stereocomplex PLA, we developed the four unit processes, fermentation, separation, lactide conversion, and polymerization. Fermentation of sugars to D-lactic acid is little studied, and its microbial productivity is not well known. Therefore, we investigated D-lactic acid fermentation with a view to obtaining the strains capable of producing D-lactic acid, and we got a maximum lactic acid production $60 \mathrm{~g} / \mathrm{L}$. Lactide is prepared by a two-step process: first, the lactic acid is converted into oligo(lactic acid) by a polycondensation reaction; second, the oligo(lactic acid) is thermally depolymerized to form the cyclic lactide via an unzipping mechanism. Through catalyst screening test for polycondensation and depolymerization reactions, we got a new method which shortens the whole reaction time $50 \%$ the level of the conventional method. Poly(L-lactide) was obtained from the ring-opening polymerization of L-lactide. We investigated various catalysts and polymerization conditions. Finally, we got the best catalyst system and the scale-up technology.

\section{Introduction}

Poly(lactic acid) (PLA) polymers have been known for a relatively long time, but the interest in these materials is only accelerating. A lot of research effort is currently concentrated on the development of polylactide resin manufacturing to make the material suitable for a wider range of products. The present industrial production of lactic acid is based on microbial carbohydrate fermentation because it is chemically and economically more feasible compared with the chemical route and enables the production of optically pure lactic acid. The optical purity of the reagent lactic acid is crucial during PLA production because small amounts of enantiomeric impurities drastically change properties such as crystallinity or biodegradation rate of the polymer. Because the fermentation broth includes a complex mixture of impurities, nutrients, and cell debris, the downstream processing of lactic acid plays a decisive role in the overall production route of PLA [1-6].
Lactide, the ring-formed dimer of lactic acid, is used in the production of high-molar-mass PLA in the ring-opening polymerization (ROP) route and is therefore an important intermediate in the industrial production of PLA. Because of the chiral nature of lactic acid, lactide exists in three different forms: L,L-lactide, D,D-lactide, and D,L-lactide. A 50:50 mixture of $\mathrm{L}, \mathrm{L}-$ and $\mathrm{D}, \mathrm{D}$-lactide is referred to as racemic lactide. Lactide is the end-product of a depolymerization process, in which a low-molar-mass LA oligomer produced by step-growth polymerization is thermally degraded by the so-called backbiting reaction. The properties of the crude lactide therefore depend on the quality of the polymer used as a reagent as well as on the depolymerization reaction parameters. In addition to lactide, the crude product often also contains water, lactic acid, lactic acid oligomers, and residual catalyst, in case it is used for the polymerization of the oligomer. Careful control of the production line starting from the monomers lactic acid and lactide to the polymerization process itself, whether it is step-growth polymerization or 


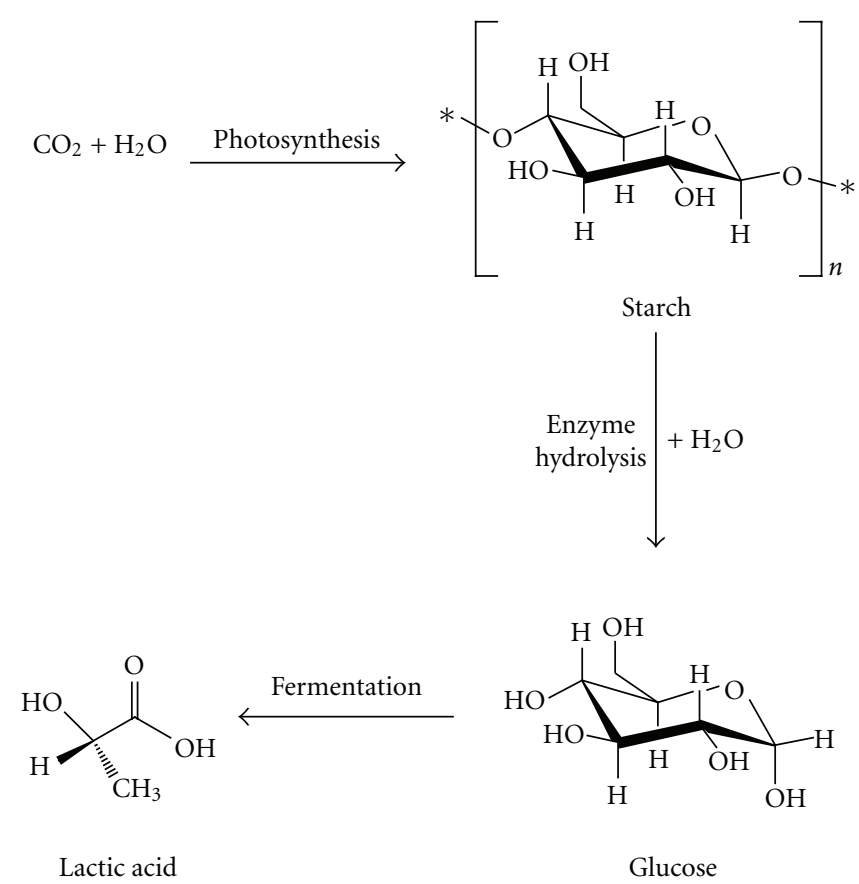

FIgUre 1: Production of Lactic acid.<smiles>CC(O)C(=O)O</smiles>
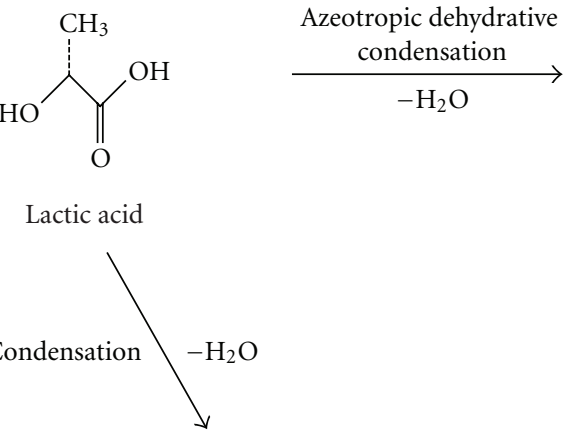<smiles>CC(O)C(=O)OC(C)C(=O)OC(C)C(=O)O</smiles>

Low-molecular-weight prepolymer $\mathrm{Mw}=1,000-5,000$<smiles>CC(O)C(=O)OC(C)C(=O)OC(C)C(=O)O</smiles>

High-molecular-weight PLA $\mathrm{Mw} \geq 100,000$

FIGURe 2: Production routes of Lactide and PLA.

ROP, is necessary for the production of optically pure highmolar-mass PLA. Figure 1 presents the simplified production routes of lactic acid and Figure 2 presents the lactide conversion from lactic acid and PLA polymerization. In addition, Figure 3 presents the three different types of lactide [7-15].

This research shows the development of four unit process technologies for PLA resin manufacturing such as fermentation, separation and purification, lactide conversion, and resin polymerization. It is expected that these results would be used for the construction of pilot plant which produce PLA resin for automotive parts application.

\section{Materials and Methods}

2.1. Lactic Acid Fermentation: Microorganism and Culture Conditions. The E. coli KCTC 2223 was obtained from the Korean National Strain Stock Center. For shake-flask experiments, strains (stored as glycerol stocks at $-80^{\circ} \mathrm{C}$ ) were first grown on $\mathrm{LB}$ medium plates for about $24 \mathrm{~h}$ at $37^{\circ} \mathrm{C}$ and subsequently colonies were transferred to $50 \mathrm{~mL}$ of $\mathrm{LB}$ medium in a $250 \mathrm{~mL}$ flask. After $10 \mathrm{~h}$ growth with shaking, cells were harvested by centrifugation and resuspended in LB medium.

For each bioreactor experiment, cells were precultured as described above and transferred to $150 \mathrm{~mL}$ medium 


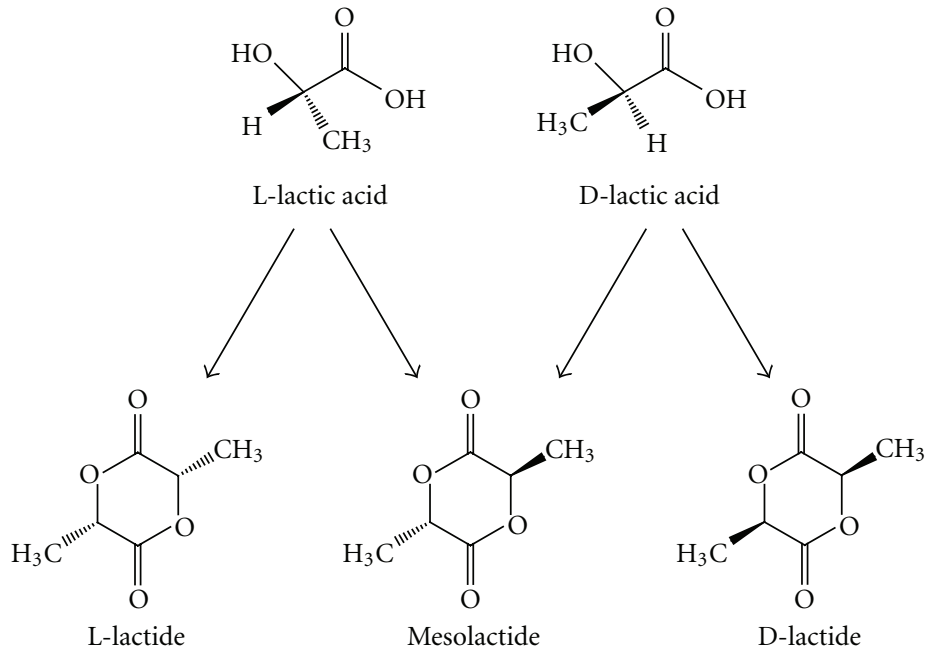

FIgure 3: Types of lactide.

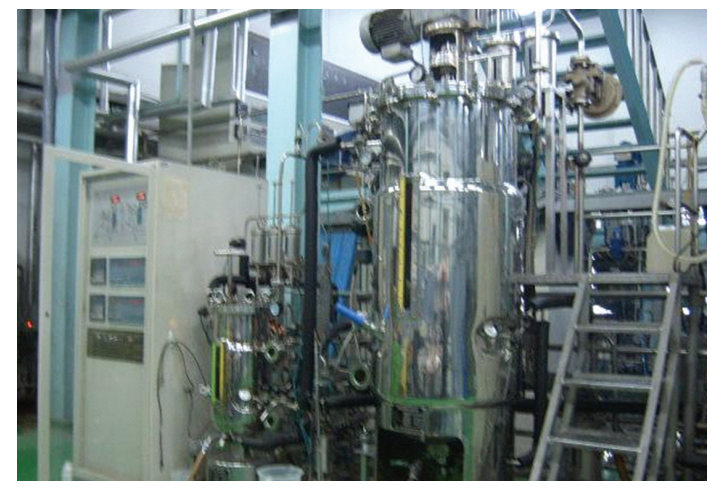

Figure 4: $300 \mathrm{~L}$ scale fermentor for lactic acid production.

containing $5 \mathrm{~g} / \mathrm{L}$ glucose (in a $500 \mathrm{~mL}$ flask). After incubation for $9 \mathrm{~h}$, this seed culture was used to inoculate a $7 \mathrm{~L}$ bioreactor containing $3 \mathrm{~L}$ medium with $30 \mathrm{~g} / \mathrm{L}$ glucose. Growth was initiated by sparging air into the bioreactor at 3 to $7 \mathrm{~L} / \mathrm{min}$ and the dissolved oxygen concentration maintained above $30 \%$ saturation by agitation at 200 to $1000 \mathrm{rpm}$. The $\mathrm{pH}$ was controlled at 7.0 by automatic feeding concentrated $\mathrm{NH}_{4} \mathrm{OH}$ ( $\left.10 \%(\mathrm{vol} / \mathrm{vol}) \mathrm{H}_{2} \mathrm{O}\right)$. The oxygen-limited phase was started when the cell concentration reached after $5 \sim 7 \mathrm{hr}$. During this second phase, air sparging was stopped, the agitation was slowed to $100 \mathrm{rpm}$, and the $\mathrm{pH}$ was controlled at 6.4. The residual glucose concentration was maintained above $10 \mathrm{~g} / \mathrm{L}$ by adding glucose. The fermentations were stopped when the glucose was exhausted. All experiments were conducted at $37^{\circ} \mathrm{C}$ and the total fermentation time was $72 \mathrm{hr}$. For the confirmation of scale-up production, fermentation was conducted in a $300 \mathrm{~L}$ bioreactor, with working volumes of $150 \mathrm{~L}$. (Figure 4). We successfully conducted a pilot-scale fermentation for the production of lactic acid concentration $60 \mathrm{~g} / \mathrm{L}$. During the fermentation process employing pure glucose as a carbon source, fermentation parameters were not substantially altered by the scaling up of the laboratoryscale fermentation to $300 \mathrm{~L}$ scale fermentations.

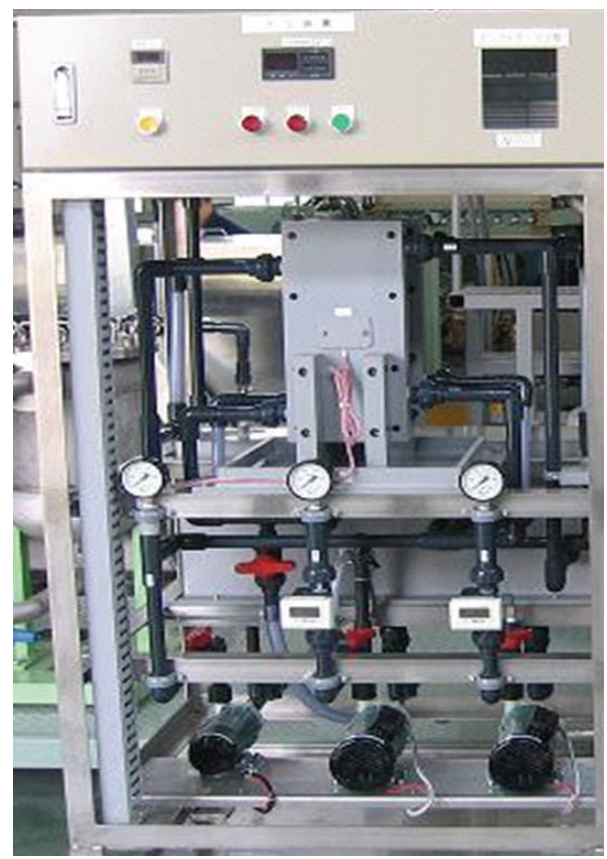

Figure 5: Pilot scale electrodialysis for separation and purification.

2.2. Separation and Purification. A number of processes for lactic acid recovery from fermentation broth without precipitation have been studied: solvent extraction, adsorption, direct distillation, and electrodialysis. These processes can make lactic acid recovery simpler and can reduce waste generation. However, solvent extraction process is disadvantageous due to unfavorable distribution coefficients. It also has environmental and economic problems of solvent loss. Adsorption process requires regeneration of ion exchange resin and adjustment of feed $\mathrm{pH}$ to increase the sorption efficiency requiring large amount of chemicals. Direct distillation can form high boiling internal esters as dimers and polymers during the distillation. Electrodialysis is an attractive process 

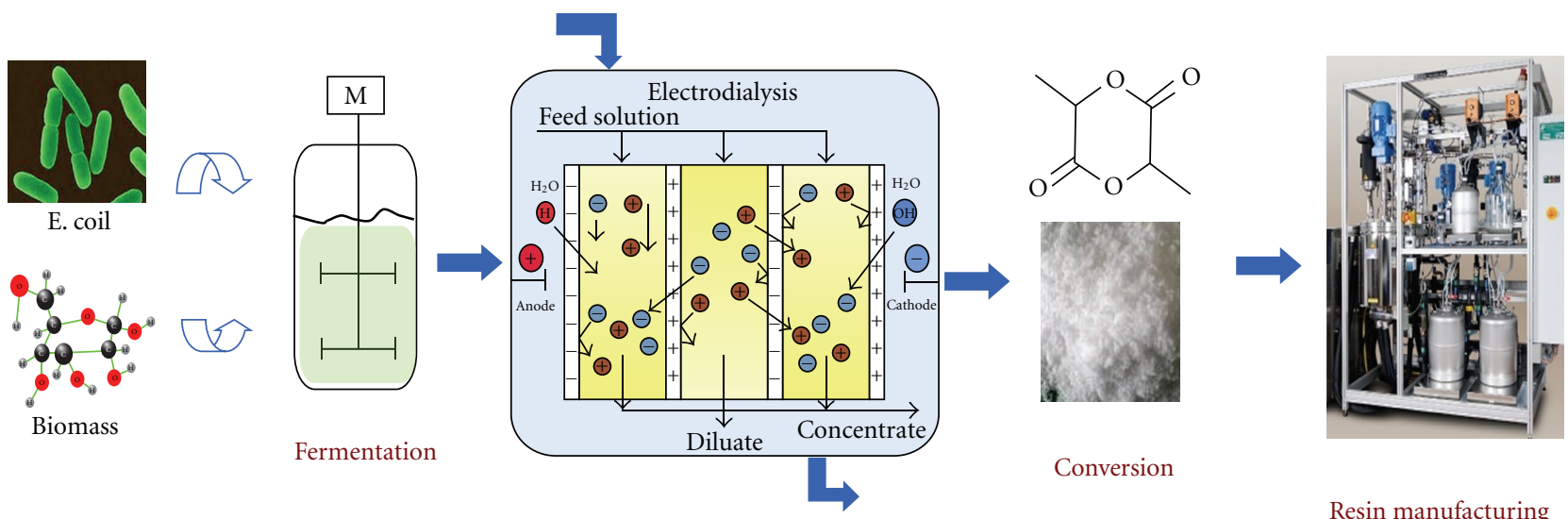

Separation/purification

Resin manufacturing

FIgURE 6: Whole process of lactic acid, lactide, and PLA manufacturing.

in the point of fast treatment, effective removal of nonionic molecules, concentration of product, and no by-product generation.

Electrodialysis is a process where ion exchange membranes are used to separate ions from an aqueous solution under the driving force of electrical potential. The equipment of desalting and water-splitting electrodialyses are illustrated in Figure 4. In desalting electrodialysis, sodium or ammonium ions in the feed move across the cation exchange membranes towards the cathode to reach the permeate compartment, and lactate ions pass through the anion exchange membranes towards the anode. Membrane water splitting technology is a general-purpose unit operation for converting water-soluble salts to their corresponding acids and bases. The process uses bipolar ion exchange membranes in conjunction with conventional cation and/or anion exchange membranes, and the separation and rearrangement of ions are effected by a direct current driving force. In the 1st desalting electrodialysis step, ammonium lactate in the fermentation broth was fed to the equipment and we got a concentrated ammonium lactate. In the second water-splitting electrodialysis step, we got a pure lactic acid successfully (Figure 5).

2.3. Lactide Conversion. In a typical process, D-, L-lactic acid was added to a reactor equipped with stirring system, vacuum-pumping system, and cooling system. After removing most of free water at $85^{\circ} \mathrm{C}$ in vacuum, catalysts (zinc oxide or $\left.\mathrm{Sn}(\mathrm{OEt})_{2}\right)$ with a mass fraction of $1 \sim 5 \%$ were added to the system. Then, the temperature of the system was increased to $150^{\circ} \mathrm{C}$ to promote the formation of oligomer and the removal of the generating water. This process was continued until no water was distilled. After that, the temperature of the system was increased to $235^{\circ} \mathrm{C}$ quickly. It can be found that large amount of yellow liquid was distilled and they crystallized into needle-like crystal after cooling. The products were recrystallized for at least 4 times in order to get highpurity and colorless lactide. The reaction conditions are as Table 1.
2.4. Polymerization. Polylactide can be synthesized by two different pathways: either the step polycondensation of lactic acid, or the ring opening polymerization (ROP) of the cyclic diester lactide. In contrast to the more traditional polycondensation, that usually requires high temperatures, long reaction times, and a continuous removal of water, to finally recover quite low-molecular-weight polymers with poor mechanical properties, lactide ROP provides a direct and easy access to the corresponding high-molecular-weight polylactide. The ring opening polymerisation of lactide is known to be promoted by Lewis acid-type catalysts such as metals, metal halogenides, oxides, aryls, and carboxylates. The main representative of this group of catalysts is tin(II)bis(2ethylhexanoate). The ring opening polymerisation is initiated by protic compounds such as water, alcohols, thiols, and amines, which are either present as impurities in the lactide dimer or can be added by demand. In this research, D-lactide was added to a $50 \mathrm{~L}$ pilot scale chemical reactor equipped with stirring system, vacuum-pumping system, and cooling system. After removing most of free water at $60^{\circ} \mathrm{C}$ and in vacuum, various catalysts and initiators were added to the reactor and polymerization reaction conducted at $180^{\circ} \mathrm{C}$ for $1 \sim 1.5 \mathrm{hr}$ (Table 2; Figure 6).

\section{Summary/Conclusions}

It was found that the strain of E. coli (KCTC 2223) can ferment the glucose to produce D-lactic acid in high conversion. Particularly, D-lactic acid with high optical purity (>99\%) was obtained in the large-scale fermentation. The total yield of D-lactic acid from the starting glucose was determined to be $\sim 50 \%$, which is almost equal to the reported yield of L-lactic acid from corn. Therefore, the D-lactic acid fermentation of glucose has high potential in its industrialization. The large-scale production of D-lactic acid may allow us to manufacture D-type PLA(PDLA), essential for successful application of the high-melting sc-PLA (stereocomplex-PLA). For PLA bioplastic with substantially improved resistance to hydrolytic degradation in high-heat 
TABLE 1: Reaction conditions of oligomer PLA and lactide manufacturing.

\begin{tabular}{|c|c|c|c|c|c|}
\hline Catalyst & $\begin{array}{l}\text { Oligomer PLA's } \\
\text { molecular weight } \\
(\mathrm{Mw})\end{array}$ & Reaction temp. $\left({ }^{\circ} \mathrm{C}\right)$ & $\begin{array}{l}\text { Reaction } \\
\text { time (hr) }\end{array}$ & $\begin{array}{l}\text { Lactide recovery } \\
\text { content }(\mathrm{kg})\end{array}$ & Image of lactide \\
\hline Without & $458 \mathrm{~g} / \mathrm{mol}$ & $150 / 235$ (step increase) & $4 / 5$ & Small & \\
\hline Without & $411 \mathrm{~g} / \mathrm{mol}$ & $150 / 235$ (step increase) & $4 / 6$ & Small & \\
\hline Without & $441 \mathrm{~g} / \mathrm{mol}$ & $150 / 235$ (step increase) & $4 / 7$ & Small & \\
\hline $\mathrm{Sn}(\mathrm{OEt})_{2}$ & $785 \mathrm{~g} / \mathrm{mol}$ & $150 / 235$ (step increase) & $4 / 4$ & Small & 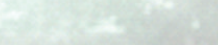 \\
\hline $\mathrm{ZnO}$ & $3354 \mathrm{~g} / \mathrm{mol}$ & $150 / 235$ (continuous increase) & $1 / 4$ & Small & \\
\hline $\mathrm{ZnO}$ & $4141 \mathrm{~g} / \mathrm{mol}$ & $150 / 235$ (continuous increase) & $1 / 3$ & Medium & $\rightarrow$ \\
\hline $\mathrm{ZnO}$ & $7760 \mathrm{~g} / \mathrm{mol}$ & $150 / 235$ (continuous increase) & $1 / 2.5$ & Large & \\
\hline
\end{tabular}

TABLE 2: Reaction conditions of oligomer PLA and lactide manufacturing.

$\begin{array}{llcl}\text { Element } & \text { Catalyst } & \begin{array}{c}\text { Reaction temp. } \\ \left({ }^{\circ} \mathrm{C}\right)\end{array} & \text { Activity } \\ \mathrm{Ca}, \mathrm{Mg} & \mathrm{Ca}(\mathrm{OMe})_{2} & 180 & \text { Low }(\mathrm{Mw}: 15,000 \mathrm{~g} / \mathrm{mol}) \\ \mathrm{Y}, \mathrm{Ti}, \mathrm{Zr} & \left(\mathrm{C}_{9} \mathrm{H}_{21} \mathrm{O}_{3}\right) \mathrm{Y} & 180 & \\ \mathrm{Al} & \mathrm{Al}(\mathrm{OiPr})_{3} & 170 & \text { Medium }(\mathrm{Mw}: 75,000 \mathrm{~g} / \mathrm{mol}) \\ \mathrm{Sn} & \mathrm{Sn}(\mathrm{Oct})_{2} & 180 & \text { High }(\mathrm{Mw}: 150,000 \mathrm{~g} / \mathrm{mol})\end{array}$

and high-humidity applications, such as automotive and electronics, it is expected that sc-PLA technology is the only solution and so the D-type lactic acid production is important.

Desalting electrodialysis for lactate recovery was operated in a constant-current and subsequent constant-voltage modes, and the switching point was determined from limiting current density measurement data. The limiting current density was proportional to lactate concentration up to $10 \mathrm{~g} / \mathrm{L}$ but it could not be found beyond this level. Therefore, the operation of desalting electrodialysis had to be switched from constant-current to constant-voltage modes when the lactate concentration was higher than $10 \mathrm{~g} / \mathrm{L}$. In our experiments the switching was done when the lactate concentration was inferred to be $11 \mathrm{~g} / \mathrm{L}$. Water-splitting electrodialysis which converts ammonium lactate to lactic acid and recovers ammonia was operated only in a constant-current mode. During the operation, the volume changes of the feed and the permeate solutions due to electro-osmosis were significant. From the volume change data, water transport index was determined. The electrical resistance of the membrane stack could be expressed with two parts, that is, one which was the inherent resistance of membranes and the other which was inversely proportional to lactate concentration in the feed. The stack resistance, especially the part of the inherent resistance of membranes significantly changed with the applied current, which requires future study.

The polycondensation of lactic acid and the depolymerization of oligomer PLA into lactide were performed with significantly improved reaction rate and yield under $\mathrm{ZnO}$ catalyst condition. Compared with noncatalyzed conventional method, reaction time taken for the preparation of lactide catalyzed by zinc oxide powder was shortened by at least $50 \%$. The effect of catalyst played a predominant role during the polycondensation, which not only significantly accelerated the rate of the polycondensation but also improved the molecular weight of the resulting oligomer PLA. Oligomer PLA with an $7760 \mathrm{~g} / \mathrm{mol}$ and yield of $85 \%$ was obtained using zinc oxide powder as a catalyst. For the depolymerization of oligomer PLA, the effect of catalyst species became obvious. Zinc oxide powder was a suitable catalyst for depolymerization reaction also.

PLA was synthesized by the direct melt polymerization using tin(II)bis(2-ethylhexanoate) as a catalyst at different polymerization time. The suitable reaction temperature was around $180^{\circ} \mathrm{C}$ and the reaction time was $1 \mathrm{hr}$. The molecular weight of resin could be controlled by changing the catalyst and initiator content. We successfully got high-molecularweight PLA. The molecular weight of PLA reached as high as 150,000 . Increasing of the content of catalyst for the reaction 
from 250 to 500 ppm downed the molecular weight of PLA from 120,000 to 75,000 .

\section{Abbreviations}

LA: Lactic acid

ROP: Ring-opening polymerization.

\section{Acknowledgment}

The authors would like to acknowledge the financial support of Hyundai-Kia Motor Company greatly.

\section{References}

[1] J. Lunt, "Large-scale production, properties and commercial applications of poly lactic acid polymers," Polymer Degradation and Stability, vol. 59, no. 1-3, pp. 145-152, 1998.

[2] R. E. Drumright, P. R. Gruber, and D. E. Henton, "Polylactic acid technology," Advanced Materials, vol. 12, no. 23, pp. 1841-1846, 2000.

[3] R. Mehta, V. Kumar, H. Bhunia, and S. N. Upadhyay, "Synthesis of poly(lactic acid): a review," Journal of Macromolecular Science-Polymer Reviews, vol. 45, no. 4, pp. 325-349, 2005.

[4] D. W. Farrington, J. Runt, S. Davies, and R. S. Blackburn, "Poly(lactic acid) fibers," in Biodegradable and Sustainable Fibres, Woodhead Publishing, 2005.

[5] E. T. H. Vink, K. R. Rábago, D. A. Glassner, and P. R. Gruber, "Applications of life cycle assessment to NatureWorks polylactide (PLA) production," Polymer Degradation and Stability, vol. 80, no. 3, pp. 403-419, 2003.

[6] R. A. Gross and B. Kalra, "Biodegradable polymers for the environment," Science, vol. 297, no. 5582, pp. 803-807, 2002.

[7] J. A. Cicero, J. R. Dorgan, J. Garrett, J. Runt, and J. S. Lin, "Effects of molecular architecture on two-step, melt-spun poly(lactic acid) fibers," Journal of Applied Polymer Science, vol. 86, no. 11, pp. 2839-2846, 2002.

[8] J. A. Cicero, J. R. Dorgan, J. Janzen, J. Garrett, J. Runt, and J. S. Lin, "Supramolecular morphology of two-step, melt-spun poly(lactic acid) fibers," Journal of Applied Polymer Science, vol. 86, no. 11, pp. 2828-2838, 2002.

[9] X. Yuan, A. F. T. Mak, K. W. Kwok, B. K. O. Yung, and K. Yao, "Characterization of poly(L-lactic acid) fibers produced by melt spinning," Journal of Applied Polymer Science, vol. 81, no. 1, pp. 251-260, 2001.

[10] G. Schmack, B. Tändler, G. Optiz et al., "High-speed melt spinning of various grades of polylactides," Journal of Applied Polymer Science, vol. 91, no. 2, pp. 800-806, 2004.

[11] J. A. Cicero, J. R. Dorgan, J. Janzen, J. Garrett, J. Runt, and J. S. Lin, "Supramolecular morphology of two-step, melt-spun poly(lactic acid) fibers," Journal of Applied Polymer Science, vol. 86, no. 11, pp. 2828-2838, 2002.

[12] S. Singh and S. S. Ray, "Polylactide based nanostructured biomaterials and their applications," Journal of Nanoscience and Nanotechnology, vol. 7, no. 8, pp. 2596-2615, 2007.

[13] S. S. Ray, K. Yamada, M. Okamoto, A. Ogami, and K. Ueda, "New polylactide/layered silicate nanocomposites. 3. Highperformance biodegradable materials," Chemistry of Materials, vol. 15, no. 7, pp. 1456-1465, 2003.

[14] V. Krikorian and D. J. Pochan, "Crystallization behavior of poly(L-lactic acid) nanocomposites: nucleation and growth probed by infrared spectroscopy," Macromolecules, vol. 38, no. 15, pp. 6520-6527, 2005.
[15] D. Zhang, M. A. Kandadai, J. Cech, S. Roth, and S. A. Curran, "Poly(L-lactide) (PLLA)/multiwalled carbon nanotube (MWCNT) composite: characterization and biocompatibility evaluation," Journal of Physical Chemistry B, vol. 110, no. 26, pp. 12910-12915, 2006. 

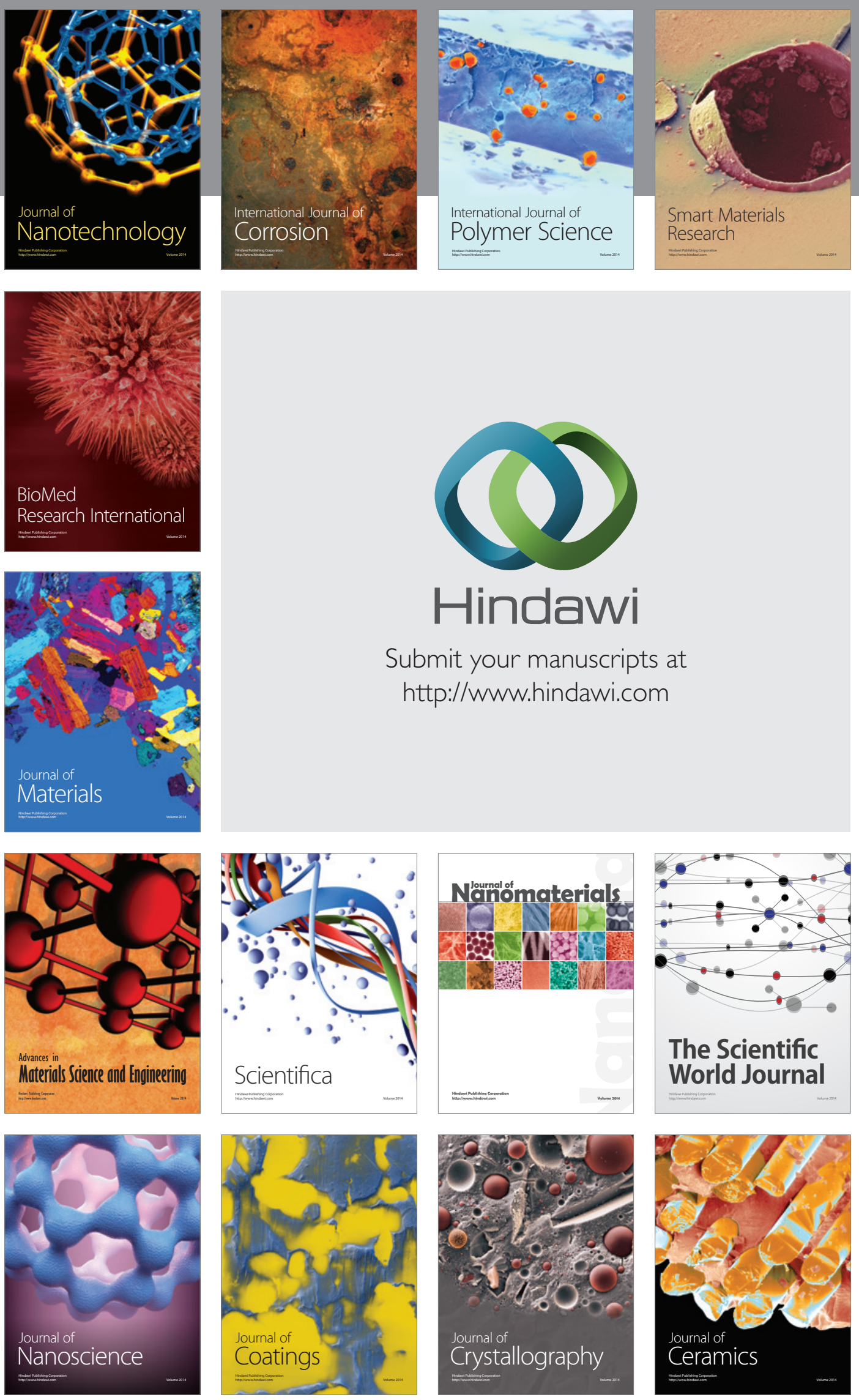

The Scientific World Journal

Submit your manuscripts at

http://www.hindawi.com

\section{World Journal}

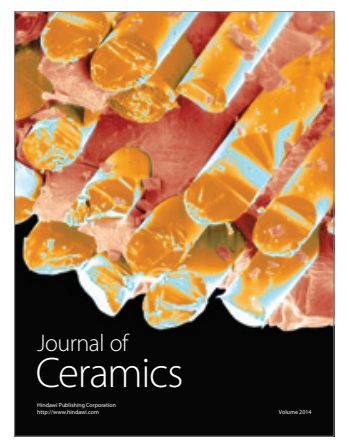

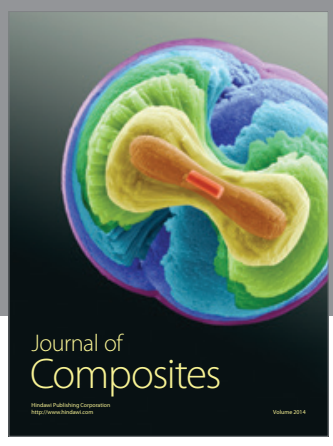
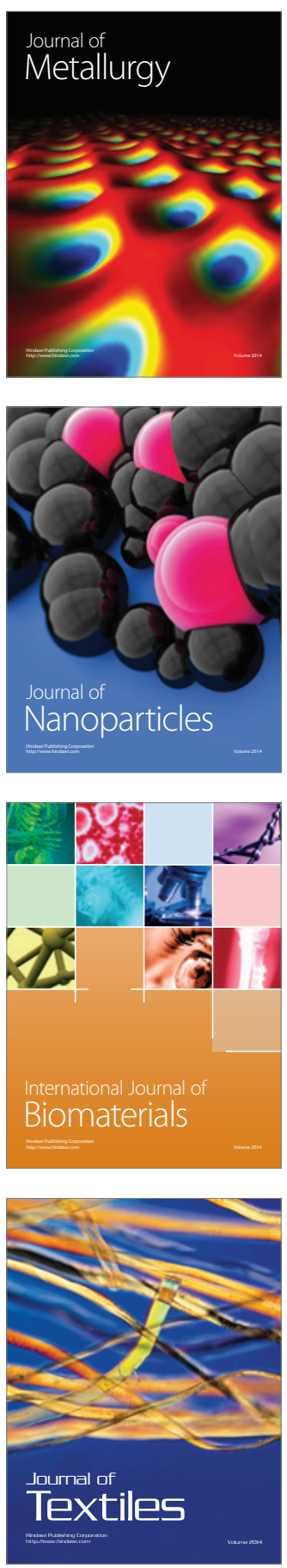